\title{
Isolation of Weissella strains as potent probiotics to improve antioxidant activity of salted squid by fermentation
}

\author{
Bao Le ${ }^{1} \cdot$ Seung Hwan Yang ${ }^{1}$ iD
}

Received: 7 February 2018 / Accepted: 19 March 2018 / Published Online: 31 March 2018

(C) The Korean Society for Applied Biological Chemistry 2018

\begin{abstract}
The aim of this study was to enhance the antioxidant activity of salted squid by inoculation of two Weissella spp. strains (W. cibaria FB-069 and W. viridescens FB-077) isolated from traditional Korea salted squid. The safety and probiotic potential characteristics of these two strains were evaluated. The safety of these strains was analyzed based on hemolytic activity, mucin degradation, biogenic amino production, and resistance to antibiotics. These lactic acid bacteria showed probiotic potential, including resistance to gastrointestinal tract conditions, adhesion to Caco-2 cells, and aggregation. The low-salted squid fermented with Weissella strains had consistently higher antioxidant activity through changing their amino acid profiles. Therefore, $W$. cibaria FB-069 and $W$. viridescens FB-077 might be good candidates for fermentation of salted squid to develop functional food with enhanced health benefits.
\end{abstract}

Keywords Antioxidant $\cdot$ Probiotic $\cdot$ Salted squid $\cdot$ Weissella

\section{Introduction}

Naturally fermented food and beverages can be classically defined as functional foods with beneficial effects for the host (Stanton et al. 2005; Leroy and De Vuyst 2014). Most fermented foods contain a variety of microorganisms that might transform chemical constituents of food sources during fermentation,

Seung Hwan Yang $(\bowtie)$

E-mail:ymichigan@jnu.ac.kr

${ }^{1}$ Department of Biotechnology, Chonnam National University, Yeosu 59626, Republic of Korea

This is an Open Access article distributed under the terms of the Creative Commons Attribution Non-Commercial License (http://creativecommons. org/licenses/by-nc/3.0/) which permits unrestricted non-commercial use, distribution, and reproduction in any medium, provided the original work is properly cited. resulting in enrichment of substrates with vitamins, essential amino acids, bioactive compound, improvement of nutrient, inhibition of pathogen, and degrading toxic components (Leroy and De Vuyst 2014; Koo et al. 2016). The consumption of fermented food has beneficial effects, including health-promoting, anti-aging, anti-carcinogenic, and anti-obesity activities. In addition, it can prevent hypertension, cardiovascular diseases, gastrointestinal disorders, diabetes, osteoporosis, and cancer (Yang et al. 2014; Koo et al. 2016). However, the clinical evidences for health benefits of fermented foods in large and long-term prospective studies is very limited (Marco et al. 2017). In addition, most naturally fermented foods in different countries and regions of the world are still at home production under traditional conditions (Dolci et al. 2015).

Fermented seafood products have many unique forms across East Asia, Southeast Asia, and Europe. Ojingeojeot is one of the highly consumed seafood products in Korea. It is produced from squid, salted, and fermented for inhibition of spoilage (Koo et al. 2016). In a previous study, we have reported the antioxidant activity of fermented squid with soymilk additive (Akther et al. 2017). It has been shown that salted squid has high anticancer activity on liver hepatocellular carcinoma cell HepG2 (Lim et al. 2001). Until now, salted squid has mainly used as an additive in kimchi fermentation. Based on consumers' demand, salted squid has a great potential to be recognized as a nutritious and palatable food product globally. Therefore, efforts on research and development of salted squid are needed.

Lactic acid bacteria (LAB) are the main group of probiotic microorganisms with several healthy benefits on the host (Markowiak and Śliżewska 2017). The most commonly used probiotics are Lactobacillus and Bifidobacterium gena. The main selection criteria for probiotics are a long history of safe use and high genotypic stability (Sanders et al. 2010). However, only a few and specially selected strains are used in functional food (Markowiak and Śliżewska 2017). Among bacteria associated with fermented squid, dominant strains are Bacillus, Staphylococcus, 
and Weissella, followed by Carnobacterium, Leuconostoc, and Pediococcus (Koo et al. 2016). Some Weissella species can cause sepsis with other health-detrimental roles in human clinical infections, whereas other species of Weissella have beneficial roles in food preservation and key functions in food fermentation (Fairfax et al. 2014). It has been shown that some Weissella strains isolated from ojingeojeot possess resistance to gastrointestinal tract and bile juice with antimicrobial activity to Listeria monocytogenes (Kim et al. 2005). Weissella cibaria has an anti-inflammatory effect on dendritic cells and in animal models (Lim et al. 2017). Nondigestible polysaccharides from Weissella $\mathrm{sp}$. have been used as prebiotics or for additive ingredients in food industries (Baruah et al. 2017; Kanimozhi et al. 2017). Some Weissella strains have been used in the preparation of functional foods. For example, the anti-obesity effect was observed in kimchi fermented with Weissella koreensis OK1-6 (Park et al. 2012). In addition, Weissella sp. mediated soymilk fermentation showed a significant increase in total isoflavone aglycones content compared to control (Chun et al. 2008).

In this paper, Weissella spp. isolated from the traditional salted squid was screened for their probiotics properties such as resistance to the gastrointestinal tract, antibiotic resistance, and their abilities of auto-aggregation and co-aggregation. We further evaluated the antioxidant activity of salted squid after inoculation with potential Weissella isolate as a starter culture.

\section{Materials and Methods}

\section{Isolation of LAB strains from traditional salted squid}

Twenty-two traditional homemade salted squid samples were collected from different cities in Jeollanam-do Province, Korea. All samples were collected in sterile tubes $(15 \mathrm{~mL})$ and kept in an icebox. After transporting to the laboratory, these samples were stored at $-20{ }^{\circ} \mathrm{C}$. Isolation of strains was finished within two days. For isolation of LAB strains, several dilutions of samples were spread onto De Man Rogosa Sharpe (MRS, Difco, Detroit, MI, USA) agar plates. After anaerobic incubation at $37{ }^{\circ} \mathrm{C}$ for $48 \mathrm{~h}$, colonies with different morphotypes were collected in MRS broth supplemented with $25 \%$ glycerol and stored at $-80{ }^{\circ} \mathrm{C}$ for further analysis.

\section{Antioxidative activity}

Each strain was cultured in MRS broth at $30{ }^{\circ} \mathrm{C}$ for $24 \mathrm{~h}$. After incubation, the cell-free cultured broth was used to determine antioxidative activity. Aliquots $(15 \mathrm{~mL})$ of each medium were taken during fermentation $(0,4,8,20,24,32$, and $44 \mathrm{~h})$ to determine cell growth and antioxidant activity. The antioxidant capacity of the supernatant was determined by four different assays: DPPH (Brand-Williams et al. 1995), ABTS (Re et al. 1999), hydroxyl (Hagerman et al. 1998), and superoxide radical scavenging activity (Robak and Gryglewski 1988). Results were expressed as scavenging activity (\%).

\section{Strain identification}

Total DNA was isolated using Genomic DNA Prep Kit (Solgent, Daejeon, South Korea) according to the manufacturer's instructions. PCR amplification of 16S rRNA gene was performed using the following primers: 27F, 5'-AGAGTTTGATCCTGGC TCAG-3'; and 1492R, 5'-GGTTACCTTGTTACGACTT-3'. The sequencing of the 16S rRNA gene was conducted by Bioneer Co. (South Korea). Sequence was analyzed for similarities by accessing data deposited at National Center for Biotechnology Information using BLAST program. A phylogenetic tree was constructed using closely related sequences showing high similarities in BLAST results followed by neighbor-joining phylogenetic tree construction using MEGA7 program.

\section{Safety assessment}

Fresh lactobacilli broth cultures (8.0-9.0 $\log \mathrm{CFU} / \mathrm{mL})$ were streaked onto agar plates in triplicates for hemolytic reaction, mucin degradation, and biogenic amines production. After $48 \mathrm{~h}$ of incubation at $37^{\circ} \mathrm{C}$, plates were examined for activities. Lactobacillus rhamnosus GG (L.GG) ATCC 53103 and S. aureus KCCM 11335 strains were used as negative and positive controls, respectively. For hemolytic activity, Columbia agar plates (DB, Difco, Detroit, MI, US) containing 5\% (w/v) defibrinate sheep blood were used. Mucin degradation was determined on $0.3 \%$ porcine stomach mucin supplied agarose medium (DB, Difco) with or without glucose. Biogenic amine production of the isolate was determined using decarboxylase medium (DB, Difco) containing 1\% separate amino acids such as L-tyrosine, L-histidine, L-ornithine, Larginine, L-phenylalanine, L-lysine, or L-tryptophan.

\section{Disc diffusion assay}

The antimicrobial activity was determined by agar disc diffusion assay based on standard protocol of Clinical and Laboratory Standards Institute (CLSI 2015). Bacillus cereus KACC 11240, Shigella boydii KACC 10792, Listeria monocytogenes KACC 10764, Yersinia enterocolitica subsp. enterocolitica KACC 15320, Escherichia coli K99 KCTC 261, Salmonella enterica serotype Choleraesuis KCTC 2932, Salmonella enterica serovar Typhi KCTC 2514, Salmonella enterica subsp. enterica serovar Gallinarum KCTC 2931, and Staphylococcus aureus KCCM 11335 were used as pathogen strains. The diameter of the clean zone around each of the discs was taken as a measure of the antimicrobial activity.

\section{Antibiotic susceptibility}

Broth microdilution assay was applied to determine antibiotic susceptibility of each strain (Patel et al. 2014). Each well contained $100 \mu \mathrm{L}$ of $5.0 \log \mathrm{CFU} / \mathrm{mL}$ of inoculum and $100 \mu \mathrm{L}$ of serially diluted (two-fold) antibiotics. Penicillin, ampicillin, vancomycin, streptomycin. kanamycin and tetracycline (Sigma-Aldrich, St 
Louis, MO, USA) were chosen according to the list proposed by the Clinical and Laboratory Standard Institute (CLSI). Plates were incubated at $37{ }^{\circ} \mathrm{C}$ and the minimum inhibitory concentration was evaluated at $24 \mathrm{~h}$ after incubation.

\section{Assessment of probiotic potential}

Tolerance to simulated GI tract condition test was performed by successively exposing test strain to oral-gastric-intestinal simulated juice as described by Damodharan et al. (2015). Bacterial viability at the end of each stress was monitored using LIVE/DEAD BacLight bacterial viability kit (Invitrogen, Eugene, Oregon, USA) following the manufacturer's protocol.

Adhesion assay was performed using human colonic cell line Caco-2 (passages 29-31) obtained from KCTC (Korea). Caco-2 cells were cultured in Dulbecco's Modified Eagle Medium (DMEM) which was routinely changed every two days until a confluent monolayer was obtained. After washing twice with PBS ( $\mathrm{pH}$ 7.2), fresh DMEM was resuspended in serum- and antibioticfree medium with $1 \mathrm{~mL}$ of bacterial suspension (8.0 log CFU/ $\mathrm{mL}$ ). After incubation at $37{ }^{\circ} \mathrm{C}$ with $5 \% \mathrm{CO}_{2}$ for $1 \mathrm{~h}$, cells were washed twice with PBS to remove non-attached bacterial cells. Cells were then detached from each well with $1 \mathrm{~mL}$ of $1 \%(\mathrm{v} / \mathrm{v})$ Triton X-100. Bacterial adhesion (\%) was determined after plating serial dilutions of the suspension onto MRS plates followed by incubation at $37{ }^{\circ} \mathrm{C}$ for $24 \mathrm{~h}$.

Specific cell-cell interactions were determined according to a published method (Xu et al. 2009). Briefly, bacterial cells were cultured overnight, centrifuged at $5000 \times \mathrm{g}$ for $10 \mathrm{~min}$ at $4{ }^{\circ} \mathrm{C}$, and washed with PBS. The cell pellet was resuspended in PBS (mixed by pipetting) to reach a final concentration of $8.0 \log \mathrm{CFU} / \mathrm{mL}$. The absorbance of bacterial suspension at $600 \mathrm{~nm}$ was measured (A0). The suspension was then incubated at $37{ }^{\circ} \mathrm{C}$ for $5 \mathrm{~h}$. The absorbance of the supernatant was then measured at $600 \mathrm{~nm}$ (An, $\mathrm{n}=1,2,3,4$, and 5). Percentage of auto-aggregation was calculated as follows:

\section{Auto-aggregation $(\%)=(\mathrm{A} 0-\mathrm{An} / \mathrm{A} 0) \times 100$}

Isolate and pathogen suspensions were prepared as described earlier for auto-aggregation followed by mixing at equal volume. They were then incubated at $37{ }^{\circ} \mathrm{C}$ for $5 \mathrm{~h}$. Absorbance values of the supernatant before and after incubation were measured at 600 $\mathrm{nm}$. Percentage of co-aggregation was calculated using the following formula:

$$
\text { Co-aggregation }(\%)=\left[1-A_{m} /\left(A_{i}+A_{p}\right) / 2\right] \times 100
$$

where $A_{p}$ and $A_{i}$ were absorbance values of the pathogen and isolated strains suspension in control tube and $\mathrm{A}_{\mathrm{m}}$ was absorbance value of mixed bacterial suspension after incubation.

\section{Preparation of salted squid fermentation}

Fresh salted squid samples were supplied by Greenmin Food Co., Yeosu, Korea. In brief, the culture was prepared using 3:1 (w/w) fresh squids and seasoning (hot pepper flakes, salt). The salted squid was inoculated with about $7.0 \log \mathrm{CFU} / \mathrm{mL}$ of isolated strains. The culture was mixed well with the bacteria and quiescently fermented at $4{ }^{\circ} \mathrm{C}$ for 0,1 , and 2 months. The nonfermented salted squid was used as control. All fermentations were carried out in triplicates.

\section{Antioxidant capacity of fermented squid samples}

For extraction of salted squid, $25 \mathrm{~g}$ of fermented sample was homogenized with $250 \mathrm{~mL}$ of ethanol : DMSO : water (70:30:1, $\mathrm{v} / \mathrm{v} / \mathrm{v}$ ) at $24,000 \mathrm{rpm}$ and stirred for $1 \mathrm{~h}$ at $25^{\circ} \mathrm{C}$. The sample was then centrifuged at $8,000 \times \mathrm{g}$ for $10 \mathrm{~min}$ to collect the supernatant. Antioxidant capacity of the supernatant was then determined as described above.

\section{Amino acid analysis}

Salted squid $(1 \mathrm{~g})$ was hydrolyzed with $100 \mathrm{~mL}$ of $6 \mathrm{M} \mathrm{HCl}$ in sealed ampoules in an oven at $110^{\circ} \mathrm{C}$ for $22 \mathrm{~h}$. The mixture was then passed through a $0.45-\mu \mathrm{m}$ membrane filter and injected into an automatic amino acid analyzer (S-433, SYKAM GmbH, Munich, Germany).

\section{Statistical analysis}

All experiments were performed in triplicates. Results are presented as mean $\pm \mathrm{SD}$ (standard deviation). One-way analysis of variance (ANOVA) and Duncan's Multiple Range Test were performed using SPSS software ver. 22, (SPSS Inc., Chicago, IL, USA). Statistical significance was considered at $p<0.05$.

\section{Results and Discussion}

\section{Selections of strains}

The safety assessment is the first criterion of probiotics to ensure that its products do not pose any risk to consumer health. Thus, these isolates were selected based on international guidelines for evaluation of probiotic potential provide by FAO/WHO (2002). If bacteria have hemolytic activity, they could be virulent and cause disease despite host resistance mechanisms. The production of a microbial enzyme capable of degrading mucin or producing biogenic amines might favor mucosal invasion by pathogens and other toxic agents indicative of food spoilage. Therefore, these properties are not considered desirable features for probiotic strains. We investigated a collection of ten LAB isolated from the traditional salted squid to determine their hemolytic ability, mucin degradation, and biogenic amine producing activities.

\section{Antioxidant activity of lactic acid bacteria}

The antioxidant activities of ten LAB isolates from salted squid were determined based on their DPPH, hydroxyl radical, and superoxide radical scavenging activities. Results are shown in Fig. 1. Among these ten strains tested, FB-069 had the highest 


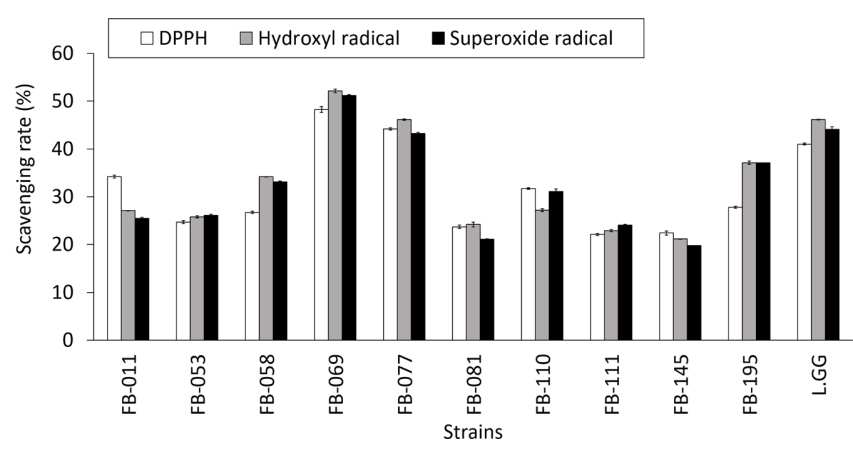

Fig. 1 Scavenging activities on DPPH, hydroxyl radicals, and superoxide radical by intracellular cell-free extracts of isolates $\left(10^{9} \mathrm{CFU} / \mathrm{mL}\right)$ incubated at $37^{\circ} \mathrm{C}$ for $18 \mathrm{~h}$. Each value is expressed as mean $\pm \mathrm{SD}(\mathrm{n}=3)$

scavenging activities for DPPH free radical, hydroxyl radical, and superoxide radical, with inhibition rates of $48.2,52.1$, and $51.2 \%$, respectively, at $9.0 \log$ CFU/mL. FB-077 strain also showed high antioxidant activity, similar to Lactobacillus rhamnosus GG. Antioxidative activities of LAB such as L. casei, L. fermentum, L.GG, and Streptococcus thermophilus have been reported in previous studies (Kim et al. 2005; Abushelaibi et al. 2017). The FB-69 strain was most similar to Weissella cibarica, whereas the FB-077 strain was clarified within $W$. viridescens based on $16 \mathrm{~S}$
rRNA gene BLAST analysis ( $>99 \%)$ and phylogenetic tree (Fig. 2).

\section{Antimicrobial activity and antibiotic susceptibility}

Two potential strains showed different antimicrobial activities as shown in Table 1. Both strains effectively inhibited the growth of Gram-negative E. coli and Salmonella spp. at various degrees. They showed the highest antimicrobial activity against $S$. gallinarum (diameter of the inhibition zone $>8 \mathrm{~mm}$ ).

The resistance of microbe to antibiotics is a negative characteristic when selecting a probiotic candidate because of the possibility of horizontal gene transfer of antibiotic-resistant genes among intestinal microbiome which might cause a serious risk for the treatment of infected patients (Ochman et al. 2000; Salyers et al. 2004). These Weissella strains were found to be resistant to kanamycin (with minimum inhibitory concentration (MIC) of $\geq 128 \mu \mathrm{g} / \mathrm{mL}$ ), vancomycin (MIC $\geq 64-128 \mu \mathrm{g} / \mathrm{mL}$ ), and tetracycline (MIC $\geq 32 \mu \mathrm{g} / \mathrm{mL}$ ) (Table 1). Until now, there are no standard methods or interpretation criteria of antimicrobial susceptibilities established for Weissella spp. by the Clinical and Laboratory Standards Institute (Patel et al. 2014). However, it has been reported that Weissella spp. are intrinsically sensitive to ampicillin but resistant to kanamycin and vancomycin (Lee et al. 2012; Medford et al. 2014).

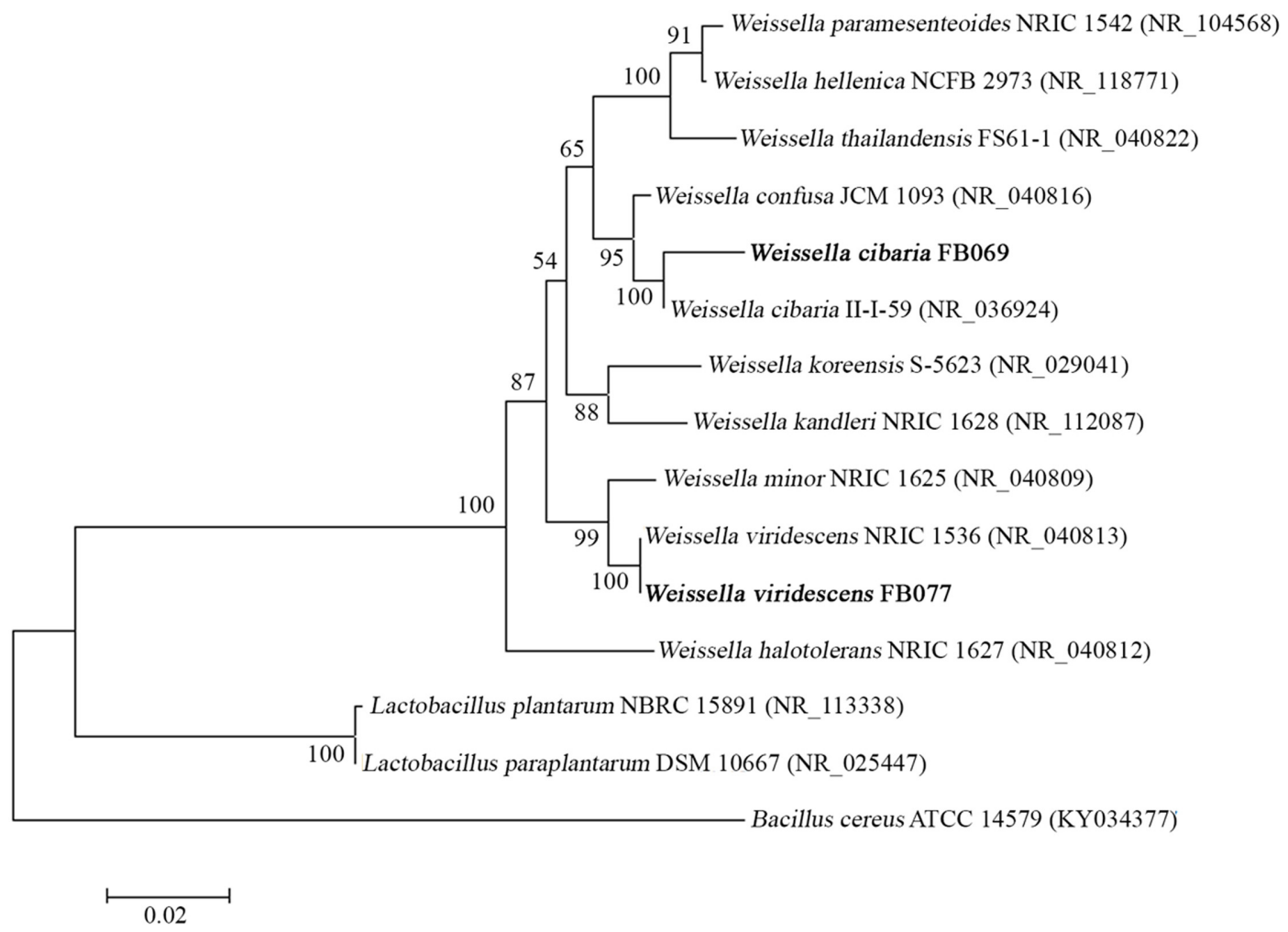

Fig. 2 Phylogenetic tree constructed based on 16S rRNA gene sequence of strains FB069, FB077 isolated from salted shrimp. The GenBank accession number is indicated in parenthesis 
Table 1 Antimicrobial activity of cell free supernatant broth of isolates against common pathogens, antibiotic resistance (MIC) and safety assessment

\begin{tabular}{|c|c|c|c|c|c|c|c|}
\hline & & FB069 & FB077 & & & FB069 & FB077 \\
\hline \multirow{9}{*}{$\begin{array}{l}\text { Pathogenic } \\
\text { strains }\end{array}$} & B. cereus & + & + & \multirow{6}{*}{$\mathrm{MIC}(\mu \mathrm{g} / \mathrm{mL})$} & Penicillin & 4 & 4 \\
\hline & E. coli $\mathrm{K} 99$ & ++ & ++ & & Ampicillin & 0.5 & 0.5 \\
\hline & L. monocytogenes & + & ++ & & Vancomycin & 64 & 128 \\
\hline & S. Gallinarum & +++ & +++ & & Streptomycin & 8 & 8 \\
\hline & S. aureus & ++ & + & & Kanamycin & 128 & 128 \\
\hline & S. Choleraesuis & ++ & ++ & & Tetracycline & 32 & 32 \\
\hline & S. Typhi & + & ++ & \multicolumn{2}{|c|}{ Bioamine production } & ND & ND \\
\hline & S. boydii & + & ++ & \multicolumn{2}{|c|}{ Hemolytic activity } & ND & ND \\
\hline & Y. enterocolitica & + & + & \multicolumn{2}{|c|}{ Mucin degradation } & ND & ND \\
\hline
\end{tabular}

+: $4 \mathrm{~mm} ;++: 8 \mathrm{~mm} ;+++$ : zone $>8 \mathrm{~mm}$

ND: non-detected

\section{(A) $\quad$ aFB-069 $\mathrm{AFB}-077$ L.GG}

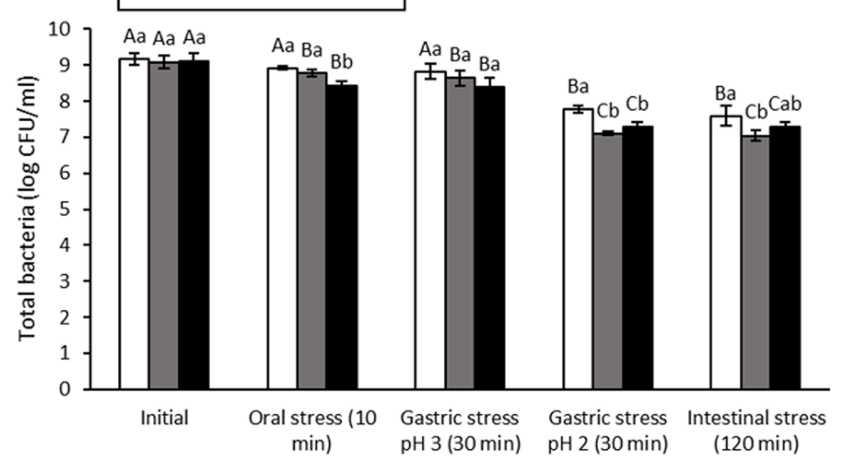

(C)

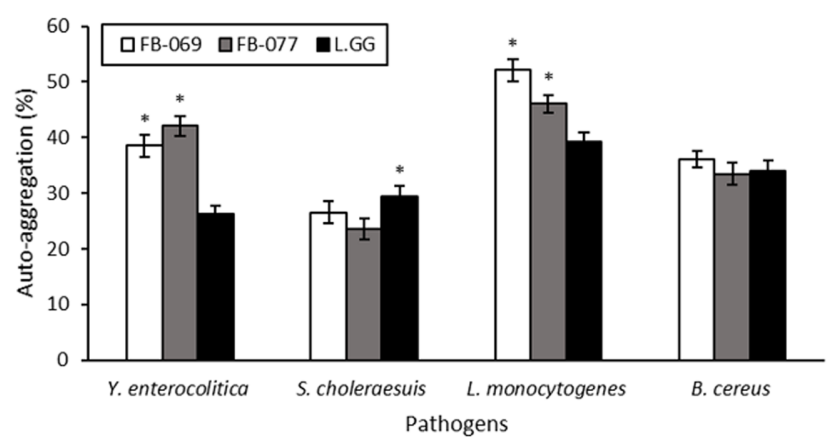

(B)

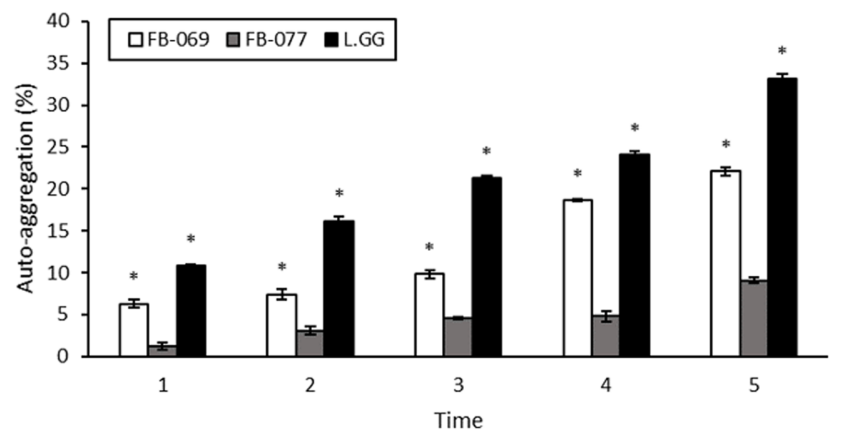

(D)

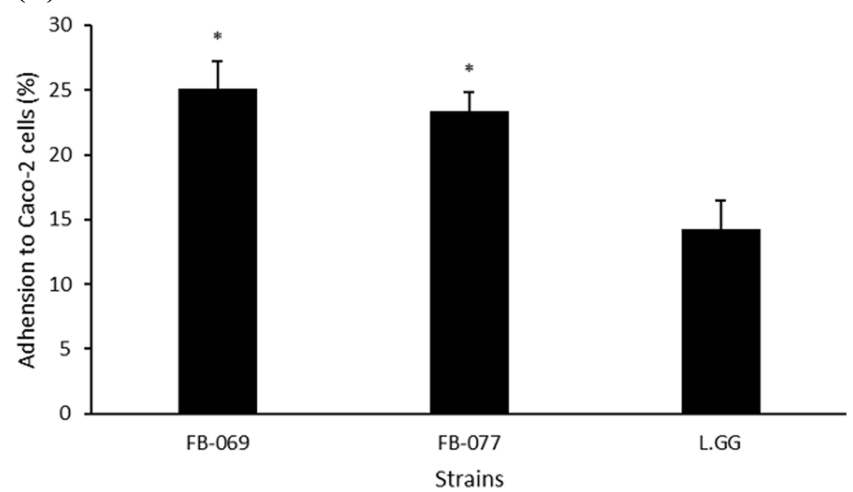

Fig. 3 Probiotic potential characteristics of isolates. (A) Tolerance of viable bacterial count different pH in gastrointestinal. Data are expressed as mean \pm SD $(n=3)$. The uppercases indicate significant difference in different $\mathrm{pH}$ values within the same isolate. The lowercases indicate significant differences among different isolates within the same $\mathrm{pH}(p<0.05)$

\section{Probiotic characteristics}

There was a significant decrease $(p \leq 0.05)$ in the population of all strains evaluated after consecutive exposure to gastric and small intestine conditions using in vitro model (Fig. 3A). W. viridescens and L.GG strains showed similar population at the end of the assay, with average survival ratio of 77.4 and $79.9 \%$, respectively, based on cell count reduction. Similar to previous observation, LAB showed good resistance to oral and intestinal environment. However, in the gastric tract, most strains were killed under extremely low pH (Lee et al. 2012; Ellis et al. 2016). The survival ability of LAB with acid stress depends on exogenous conditions which can affect intracellular $\mathrm{pH}$ and cell membrane functionality and induce stress-response proteins of microbes (Wu et al. 2014).

Results for the percentage of auto-aggregation of the two Weissella isolates and reference strain are shown in Fig. 3B. After $5 \mathrm{~h}$ of auto-aggregation, $W$. viridescens FB-069 showed the least auto-aggregative ability $(9.1 \pm 0.31 \%, p \leq 0.05)$ whereas L.GG showed the highest $(33.2 \pm 0.53 \%)$. Auto-aggregation can enhance 
gastrointestinal persistence of a probiotic in vivo as well as its colonization in vitro (Cesena et al. 2001). Auto-aggregation results of our study are consistent with results reported by others (Angmo et al. 2016; Abushelaibi et al. 2017).

Results of co-aggregation between Weissella strains and $Y$. enterocolitica, S. choleraesuis, L. monocytogenes, or B. cereus are shown in Fig. 3C. Compared to L.GG, W. cibaria showed higher co-aggregation abilities with $Y$. enterocolitica (38.5\%) and $L$. monocytogenes $(52.1 \%)$. In general, the co-aggregation ability of Weissella genus was strains-specific. The Weissella strains had lower co-aggregation abilities with $S$. choleraesuis Gram-negative pathogens compared to other tested pathogens.

Adhesion rates of both Weissella isolates were higher compared to the reference L.GG strain $(p \leq 0.05)$ (Fig. 3D). Although adhesion of microbes on intestinal epithelial cells has been used as a strategy to select probiotics, a wide range of adhesion abilities of probiotics to human cells have been reported recently (Yadav et al. 2015; Ellis et al. 2016). Moreover, results obtained from adhesion tests are different from the reality in vivo because of the sensitive and specific human GI tract may change the strain's adhesion ability (Vinderola et al. 2017).

\section{Antioxidant capacity of salted squid}

In general, fermentation of food with LAB to improve nutritional quality and health benefits of fermented foods has been recognized for a long time (Koo et al. 2016). In the present study, DPPH and hydroxyl radical scavenging capacities of salted squid fermented with Weissella spp. were significantly increased compared to salted squid without inoculation of bacteria after two months of fermentation (Table 2). DPPH inhibition was slightly increased 18.7 and $20.2 \%$, respectively, after two months of incubation. The similar pattern of DPPH value was similar to that of hydroxyl radical value for both Weissella strains. Those salted squids inoculated by Weissella bacteria showed significantly $(p<0.05)$ higher hydroxyl radical scavenging activity compared to control fermentation. However, ABTS free radical scavenging capacity of all salted squid sample was not increased even after two months of fermentation. $W$. cibaria FB-069 strain showed higher antioxidant effect on superoxide radical scavenging activity of salted squid. However, the antioxidant effect of salted squid was not significantly changed after inoculation with $W$. viridescens FB-077. Lee and Kim (2012) have studied the antioxidant activity of salted squid extracted from low-salted fermented squid and commercial high salted squid and found that hydroxyl radical scavenging activities are in range of 20.4 to $25.2 \%$. In another study, incorporation of W. confusa LK4 at a dose of $7.0 \log \mathrm{CFU} / \mathrm{mL}$ showed an increase of $16.9 \%$ in radical scavenging activity and a decrease of $19.41 \%$ in Korean leek fermentation compared to spontaneous fermentation (Yang et al. 2014). They confirmed that the higher antioxidant in fermented samples could be due to more production of bioactive compounds such as flavonoid, poly-phenolic compounds, and amino acids.

\section{Nutritional analysis}

Amino acid profiles of salted squid changed between the beginning and after 2-month of fermentation with the two isolates of Weissella (Table 3). Weissella spp. inoculated in salted squid were found to harbor different dominating amino acids such as proline, glutamine, arginine, threonine, and lysine. They appeared to remain stable over time. Threonine, glutamine, and isoleucine were increased significantly while serine, glycine, and alanine were decreased significantly during both fermentation. The total essential amino acid content was initially $37.1 \%$. It was increased $(p<0.05)$ to 40.0 and $41.3 \%$ after two months of fermentation with $W$. cibaria FB-069 and $W$. viridescens FB-077, respectively. These percentages are adequate as ideal protein food based on WHO criteria: $26.5 \%$ for infants, $22.6 \%$ for children, and $21.7 \%$ for adults (WHO 2007). Total neutral amino acids and alkaline amino acids content showed slight change but significant $(p<0.05)$ decrease in both fermentation. Predicted efficiency ratio (P-PER) is one of the quality parameter used for protein evaluation. P-PER values of $W$. cibaria FB-069 and $W$. viridescens FB-077 salted squid were 1.3 and 1.6, respectively. They are close to the P-PER value of 1.21 for cowpea and 1.22 for tuber anchote (Salunkhe

Table 2 Antioxidant activities of the extracts from salted squid (SS)

\begin{tabular}{|c|c|c|c|c|c|}
\hline \multirow{2}{*}{ Time (month) } & \multirow{2}{*}{ Fermentation } & \multicolumn{4}{|c|}{ Inhibitory activity (\%) } \\
\hline & & DPPH & ABTS & Hydroxyl radical & Superoxide \\
\hline \multirow{3}{*}{0} & $\mathrm{SS}+\mathrm{FB}-069$ & $22.1 \pm 0.23^{\text {defh }}$ & $23.9 \pm 0.31^{\mathrm{de}}$ & $23.7 \pm 0.47^{\mathrm{def}}$ & $17.1 \pm 0.35^{\mathrm{i}}$ \\
\hline & SS + FB-077 & $23.4 \pm 0.25^{\mathrm{def}}$ & $24.1 \pm 0.51^{\mathrm{de}}$ & $24.1 \pm 0.15^{\mathrm{de}}$ & $18.1 \pm 0.51^{\mathrm{hi}}$ \\
\hline & SS without fermentation & $23.1 \pm 0.69^{\mathrm{def}}$ & $24.1 \pm 0.54^{\mathrm{de}}$ & $24.4 \pm 0.61^{\mathrm{de}}$ & $17 \pm 0.56^{\mathrm{i}}$ \\
\hline \multirow{3}{*}{1} & $\mathrm{SS}+\mathrm{FB}-069$ & $28.1 \pm 2.31^{\mathrm{c}}$ & $31.1 \pm 0.06^{\mathrm{b}}$ & $30.7 \pm 2.93^{\mathrm{b}}$ & $20.9 \pm 0.64^{\text {fh }}$ \\
\hline & SS + FB-077 & $27.2 \pm 0.61^{\mathrm{c}}$ & $32.5 \pm 0.05^{\mathrm{b}}$ & $30.8 \pm 4.12^{\mathrm{b}}$ & $21.1 \pm 0.64^{\mathrm{efh}}$ \\
\hline & SS without fermentation & $24.1 \pm 0.64^{\mathrm{de}}$ & $31.5 \pm 0.91^{b}$ & $26.4 \pm 0.61^{\mathrm{cd}}$ & $20.1 \pm 0.22^{\mathrm{hi}}$ \\
\hline \multirow{3}{*}{2} & SS + FB-069 & $31.1 \pm 0.25^{b}$ & $32.4 \pm 0.25^{\mathrm{b}}$ & $35.2 \pm 0.81^{\mathrm{a}}$ & $24.5 \pm 2.34^{\mathrm{de}}$ \\
\hline & $\mathrm{SS}+\mathrm{FB}-077$ & $31.5 \pm 0.71^{\mathrm{b}}$ & $32.1 \pm 0.06^{\mathrm{b}}$ & $36.1 \pm 0.9^{\mathrm{a}}$ & $22.1 \pm 0.12^{\text {defh }}$ \\
\hline & SS without fermentation & $26.2 \pm 2.32^{\mathrm{cd}}$ & $32.6 \pm 0.1^{\mathrm{b}}$ & $31.1 \pm 5.22^{\mathrm{b}}$ & $20.3 \pm 0.9^{\mathrm{hi}}$ \\
\hline
\end{tabular}

Data were expressed as mean \pm standard deviation. Different superscript lowercase letters indicated statistical significance $(p<0.05)$ 
Table 3 Total amino acid profiles of salted squid (SS)

\begin{tabular}{|c|c|c|c|}
\hline \multirow{3}{*}{ Amino acid } & \multicolumn{3}{|c|}{ Fermentation period } \\
\hline & \multirow{2}{*}{$\frac{0 \text { month }}{\text { SS without fermentation }}$} & \multicolumn{2}{|c|}{2 months } \\
\hline & & SS + FB-069 & SS + FB-077 \\
\hline Asp & $8.4 \pm 0.26^{\mathrm{Bb}}$ & $9.4 \pm 0.21^{\mathrm{Ad}}$ & $8.5 \pm 0.22^{\mathrm{Bd}}$ \\
\hline Thr & $3.32 \pm 0.21^{\mathrm{Bcd}}$ & $7.2 \pm 0.42^{\mathrm{Ae}}$ & $9.1 \pm 0.11^{\mathrm{Acd}}$ \\
\hline Ser & $4.21 \pm 0.63^{\mathrm{Bc}}$ & $3.6 \pm 0.31^{\mathrm{Ah}}$ & $2.4 \pm 0.51^{\mathrm{Aj}}$ \\
\hline Glu & $4.31 \pm 1.31^{\mathrm{Bc}}$ & $11.2 \pm 0.42^{\mathrm{Ab}}$ & $9.4 \pm 0.57^{\mathrm{Ac}}$ \\
\hline Gly & $5.1 \pm 0.66^{\mathrm{Ac}}$ & $2.5 \pm 0.15^{\mathrm{Cj}}$ & $3.5 \pm 0.12^{\mathrm{Bi}}$ \\
\hline Ala & $8.1 \pm 0.91^{\mathrm{Ab}}$ & $3.4 \pm 0.38^{\mathrm{Bh}}$ & $3.6 \pm 0.51^{\mathrm{Bi}}$ \\
\hline Cys & $1.2 \pm 0.06^{\mathrm{e}}$ & $1.3 \pm 0.51^{\mathrm{k}}$ & $1.6 \pm 0.34^{\mathrm{j}}$ \\
\hline Val & $4.8 \pm 0.11^{\mathrm{c}}$ & $4.6 \pm 0.51^{\mathrm{g}}$ & $4.7 \pm 0.26 \mathrm{~g}^{\mathrm{h}}$ \\
\hline Met & $2.1 \pm 0.12^{\text {Bde }}$ & $2.6 \pm 0.42^{\mathrm{ABij}}$ & $3.6 \pm 0.87^{\mathrm{Ai}}$ \\
\hline Ile & $4.9 \pm 0.33^{\mathrm{Bc}}$ & $5.4 \pm 0.13^{\mathrm{Af}}$ & $5.7 \pm 0.13^{\mathrm{Af}}$ \\
\hline Leu & $8.9 \pm 0.22^{\mathrm{Aab}}$ & $4.6 \pm 0.01^{\mathrm{Bg}}$ & $5.4 \pm 0.71^{\mathrm{Bfg}}$ \\
\hline Tyr & $3.5 \pm 0.38^{\mathrm{cd}}$ & $3.1 \pm 0.56^{\mathrm{hi}}$ & $3.5 \pm 1.11^{\mathrm{i}}$ \\
\hline Phe & $4.1 \pm 0.19^{c}$ & $4.2 \pm 0.21^{\mathrm{g}}$ & $4.3 \pm 0.25^{\mathrm{hi}}$ \\
\hline Lys & $7.2 \pm 0.31^{\mathrm{Bb}}$ & $9.8 \pm 0.34^{\mathrm{Ad}}$ & $6.8 \pm 0.21^{\mathrm{Be}}$ \\
\hline His & $1.8 \pm 0.52^{\mathrm{de}}$ & $1.6 \pm 0.24^{\mathrm{k}}$ & $1.7 \pm 0.51^{\mathrm{j}}$ \\
\hline $\operatorname{Arg}$ & $10.3 \pm 0.11^{\mathrm{b}}$ & $10.4 \pm 0.21^{\mathrm{c}}$ & $10.6 \pm 0.34^{\mathrm{b}}$ \\
\hline Pro & $17.8 \pm 0.39^{\mathrm{Aa}}$ & $15.1 \pm 0.11^{\mathrm{Ba}}$ & $15.6 \pm 0.32^{\mathrm{Ba}}$ \\
\hline Total essential amino acids & $37.12 \pm 0.25$ & $40 \pm 0.29$ & $41.3 \pm 0.38$ \\
\hline Total neutral amino acids & $55.8 \pm 0.37$ & $42.4 \pm 0.24$ & $46.4 \pm 0.4$ \\
\hline Total acidic amino acids & $12.71 \pm 1.57$ & $20.6 \pm 0.63$ & $17.9 \pm 0.79$ \\
\hline Total alkaline amino acids & $19.3 \pm 0.31$ & $21.8 \pm 0.26$ & $19.1 \pm 0.35$ \\
\hline Total sulfur amino acids & $3.3 \pm 0.09$ & $3.9 \pm 0.47$ & $5.2 \pm 0.61$ \\
\hline Total aromatic aminon acids & $9.4 \pm 0.21$ & $8.9 \pm 0.34$ & $9.5 \pm 0.25$ \\
\hline Leu/Ile ratio & $1.8 \pm 0.11$ & $0.8 \pm 0.12$ & $0.9 \pm 0.41$ \\
\hline P-PER & $3.21 \pm 0.31$ & $1.29 \pm 0.12$ & $1.62 \pm 0.51$ \\
\hline
\end{tabular}

Data were expressed as mean \pm standard deviation. The superscript uppercases indicate significant difference in each amino acid. The lowercases indicate significant differences among the same salted squid sample $(p<0.05)$

and Kadam 1989; Ayalew et al. 2017). However, they are lower than the P-PER value of 2.5 for reference casein from cow's milk protein (WHO 1985). The amino acid imbalance is highly related to the development of serious diseases because of decreases of activity levels, food consumption, and absolute protein intake (WHO 2007). Taken together, our results showed that the nutritional quality of salted squid was improved through fermentation with Weissella strains.

The results of this study could be very useful to the selection of beneficial bacteria to develop low-salted squid as functional food or food additive with health benefits. In the present work, the safety and probiotics properties of $W$. cibaria FB-069 and $W$. viridescens FB-077 were identified. Both strains could enhance the bioactivity of salted squid. Overall, the antioxidant activity increased with the increasing fermentation time with both strains. They showed highly effective antioxidant properties, especially scavenging abilities for DPPH and hydroxyl radicals. These results suggest that Weissella strains may be potent alternative natural bacteria as starter culture for low-salted squid. The future investigations should explore the efficacy of Weissella genus in fermented process and in vivo experimental model.
Acknowledgments This work (Grants No. C0499996) was supported by Business for Cooperative R\&D between Industry, Academy, and Research Institute funded Korea Small and Medium Business Administration in 2017.

\section{References}

Abushelaibi A, Al-Mahadin S, El-Tarabily K, Shah NP, Ayyash M (2017) Characterization of potential probiotic lactic acid bacteria isolated from camel milk LWT-Food Science and Technology 79: 316-325

Akther F, Cheng J, Yang SH, Chung G (2017) Differential anticancer effect of fermented squid jeotgal due to varying concentrations of soymilk additive J Appl Biol Chem 60: 133-136

Angmo K, Kumari A, Bhalla TC (2016) Probiotic characterization of lactic acid bacteria isolated from fermented foods and beverage of Ladakh LWT-Food Science and Technology 66: 428-435

Ayalew Y, Retta N, Desse G, Mohammed A, Mellesse A (2017) Amino acid profile and protein quality in tuber and leaf of Coccnia abyssinica (Lam.)(Cogn.) accessions of Ethiopia Food science \& nutrition 5: 722729

Baruah R, Maina NH, Katina K, Juvonen R, Goyal A (2017) Functional food applications of dextran from Weissella cibaria RBA12 from pummelo (Citrus maxima) Int J Food Microbiol 242: 124-131

Brand-Williams W, Cuvelier M-E, Berset C (1995) Use of a free radical method to evaluate antioxidant activity LWT-Food science and Technology 
28: $25-30$

Cesena C, Morelli L, Alander M, Siljander T, Tuomola E, Salminen S, Mattila-Sandholm T, Vilpponen-Salmela T, Von Wright A (2001) Lactobacillus crispatus and its nonaggregating mutant in human colonization trials J Dairy Sci 84: 1001-1010

Chun J, Kim JS, Kim JH (2008) Enrichment of isoflavone aglycones in soymilk by fermentation with single and mixed cultures of Streptococcus infantarius 12 and Weissella sp. 4 Food Chem 109: 278-284

CLSI (2015) Performance standards for antimicrobial disk susceptibility tests; approved standard (12 ed) National Committee for Clinical Laboratory Standards Wayne, Villanova

Damodharan K, Lee YS, Palaniyandi SA, Yang SH, Suh J-W (2015) Preliminary probiotic and technological characterization of Pediococcus pentosaceus strain KID7 and in vivo assessment of its cholesterollowering activity Frontiers in microbiology 6: 768

Dolci P, Alessandria V, Rantsiou K, Cocolin L (2015) Advanced methods for the identification, enumeration, and characterization of microorganisms in fermented foods Advances in Fermented Foods and Beverages: Improving Quality, Technologies and Health BenefitsWoodhead Publishing Series in Food Science, Technology and Nutrition Elsevier

Ellis ML, Dowell AE, Li X, and Knight J (2016) Probiotic properties of Oxalobacter formigenes: an in vitro examination Arch Microbiol 198: 1019-1026

Fairfax MR, Lephart PR, and Salimnia H (2014) Weissella confusa: problems with identification of an opportunistic pathogen that has been found in fermented foods and proposed as a probiotic Frontiers in microbiology 5

FAO/WHO J (2002) WHO working group report on drafting guidelines for the evaluation of probiotics in food London, Ontario

Hagerman AE, Riedl KM, Jones GA, Sovik KN, Ritchard NT, Hartzfeld PW, Riechel TL (1998) High molecular weight plant polyphenolics (tannins) as biological antioxidants J Agric Food Chem 46: 1887-1892

Kanimozhi J, Moorthy IG, Sivashankar R, Sivasubramanian V (2017) Optimization of dextran production by Weissella cibaria NITCSK4 using Response Surface Methodology-Genetic Algorithm based technology Carbohydr Polym 174: 103-110

Kim S-J, Ma S-J, Kim H-L (2005) Probiotic properties of lactic acid bacteria and yeasts isolated from Korean traditional food, Jeot-gal Korean Journal of Food Preservation 12: 184-189

Koo OK, Lee SJ, Chung KR, Jang DJ, Yang HJ, Kwon DY (2016) Korean traditional fermented fish products: jeotgal Journal of Ethnic Foods 3: $107-116$

Lee K-G, Kim S-M (2012) Quality changes in low-salted squid Jeot-gal during fermentation and determination of shelf-life Journal of the Korean Society of Food Science and Nutrition 41: 687-694

Lee KW, Park JY, Jeong HR, Heo HJ, Han NS, Kim JH (2012) Probiotic properties of Weissella strains isolated from human faeces Anaerobe 18: 96-102

Leroy F, De Vuyst L (2014) Fermented food in the context of a healthy diet: how to produce novel functional foods? Curr Opin Clin Nutr Metab Care 17: $574-581$

Lim HS, Kim SH, Yoo EJ, Kang DS, Choi MR, Song SH (2001) Anticancer effect of extracts from the marine and salted fish products Korean J Life Sci 11: 48-53

Lim SK, Kwon M-S, Lee J, Oh YJ, Jang J-Y, Lee J-H, Park HW, Nam Y-D, Seo M-J, Roh SW (2017) Weissella cibaria WIKIM28 ameliorates atopic dermatitis-like skin lesions by inducing tolerogenic dendritic cells and regulatory $\mathrm{T}$ cells in BALB/c mice Sci Rep 7: 40040
Marco ML, Heeney D, Binda S, Cifelli CJ, Cotter PD, Foligne B, Gänzle M, Kort R, Pasin G, Pihlanto A (2017) Health benefits of fermented foods: microbiota and beyond Curr Opin Biotechnol 44: 94-102

Markowiak P, Eli_ewska K (2017) Effects of probiotics, prebiotics, and synbiotics on human health Nutrients 9: 1021

Medford R, Patel SN, Evans GA (2014) A confusing case-Weissella confusa prosthetic joint infection: A case report and review of the literature Canadian Journal of Infectious Diseases and Medical Microbiology 25: 173-175

Ochman H, Lawrence JG, Groisman EA (2000) Lateral gene transfer and the nature of bacterial innovation Nature 405: 299-304

Park JA, Tirupathi Pichiah P, Yu JJ, Oh SH, Daily J, Cha YS (2012) Antiobesity effect of kimchi fermented with Weissella koreensis OK16 as starter in highfat dietinduced obese C57BL/6J mice J Appl Microbiol 113: $1507-1516$

Patel JB, Cockerill FR, Alder J, Bradford PA, Eliopoulos GM, Hardy D, Hindler JA, Jenkins SG, Lewis JS, Miller LA (2014) Performance standards for antimicrobial susceptibility testing; twenty-fourth informational supplement CLSI standards for antimicrobial susceptibility testing 34: 1226

Re R, Pellegrini N, Proteggente A, Pannala A, Yang M, Rice-Evans C (1999) Antioxidant activity applying an improved ABTS radical cation decolorization assay Free Radic Biol Med 26: 1231-1237

Robak J, Gryglewski RJ (1988) Flavonoids are scavengers of superoxide anions Biochem Pharmacol 37: 837-841

Salunkhe DK, Kadam SS (1989) CRC handbook of world food legumes: nutritional chemistry, processing technology, and utilization. Boca Raton

Salyers AA, Gupta A, Wang Y (2004) Human intestinal bacteria as reservoirs for antibiotic resistance genes Trends Microbiol 12: 412-416

Sanders ME, Akkermans LM, Haller D, Hammerman C, Heimbach JT, Hörmannsperger G, Huys G (2010) Safety assessment of probiotics for human use Gut microbes 1: 164-185

Stanton C, Ross RP, Fitzgerald GF, Van Sinderen D (2005) Fermented functional foods based on probiotics and their biogenic metabolites Curr Opin Biotechnol 16: 198-203

Vinderola G, Gueimonde M, Gomez-Gallego C, Delfederico L, Salminen S (2017) Correlation between in vitro and in vivo assays in selection of probiotics from traditional species of bacteria Trends Food Sci Technol 68: 83-90

WHO J (1985) FAO/WHO/UNU, Energy and Protein Requirements Report of a joint $\mathrm{FAO} / \mathrm{WHO} / \mathrm{UNU}$ expert consultation, Geneva

WHO J (2007) Protein and amino acid requirements in human nutrition World Health Organ Tech Rep Ser: 1

Wu C, Huang J, Zhou R (2014) Progress in engineering acid stress resistance of lactic acid bacteria Appl Microbiol Biotechnol 98: 1055-1063

Xu H, Jeong HS, Lee HY, Ahn J (2009) Assessment of cell surface properties and adhesion potential of selected probiotic strains Lett Appl Microbiol 49: 434- 442

Yadav AK, Tyagi A, Kumar A, Saklani AC, Grover S, Batish VK (2015) Adhesion of indigenous Lactobacillus plantarum to gut extracellular matrix and its physicochemical characterization Arch Microbiol 197: $155-164$

Yang J, Ji Y, Park H, Lee J, Park S, Yeo S, Shin H, Holzapfel WH (2014) Selection of functional lactic acid bacteria as starter cultures for the fermentation of Korean leek (Allium tuberosum Rottler ex Sprengel.) Int J Food Microbiol 191: 164-171 